\title{
Incidence and Predictors of Pacemaker Implant Post Commercial Approval of the CoreValve System for TAVR
}

\author{
DAVID LUKE, MD, MARY HUNTSINGER, ACNP, STEVEN K. CARLSON, MD, ROY LIN, MD, \\ HAN TUN, MPH, RAY V. MATTHEWS, MD, TOMAS KONECNY, MD, PhD, \\ PHILIP CHANG, MD, FHRS and RAHUL N. DOSHI, MD, FHRS
}

Keck Medical Center of USC, University of Southern California School of Medicine, Los Angeles, CA

\begin{abstract}
Since the Medtronic CoreValve(C) (Medtronic Inc., Minneapolis, MN) gained commercial approval, there has been increased usage of the system for transcatheter aortic valve replacement (TAVR). Prior studies report the incidence of post-CoreValve $@$ permanent pacemaker implantation (PPI) rates between $18 \%$ and $34 \%$. However, populations implanted post-market approval (PMA) may have different risks from that in the United States Pivotal Trial, and the next generation Evolut(C) valve (Medtronic Inc., Minneapolis, MN) may have lower risks of PPI post TAVR. A single-center retrospective chart review of patients implanted with the CoreValve $\mathbb{P}$ PA was compared with our single-center experience in United States Pivotal Trial from July 2011 to May 2016. The original CoreValve(C population was also compared with patients receiving the newer Evolut(C) valve. Univariate and multivariate analysis was performed to identify predictors of PPI. A total of 140 patients were included in this analysis, 113 with the CoreValve@ and 27 with Evolut(C) valve. Patients undergoing PPI after CoreValve( ) were $81.2 \pm 8.9$ years old and $51.4 \%$ male. Patients in the PMA and Evolut(C) groups were younger compared with the Pivotal Trial, and patients receiving the Evolut(C) valve were more likely female. The PPI rate in the total population was $39.3 \%(N=140)$. The PPI rate in the PMA group was $44.9 \%$ versus $40.0 \%$ in the Pivotal Trial group $(p=0.63)$. In the Evolut $(\mathrm{C}$ population, the PPI rate was $22.2 \%$ compared with $41.2 \%$ for the total CoreValve $₫$ population $(p=0.04)$. Prior conduction disease and atrial fibrillation were found to be significant risk factors for pacemaker implantation (OR 2.62, $p=0.04$ and OR 2.29, $p=0.05)$. There were no factors identified that were predictive of PPI within the comparison groups. Despite a more favorable risk profile in the PMA group, PPI remained comparable in the two groups implanted with the CoreValve $\subset$ system. The Evolut $\mathbb{C}$ valve is associated with a lower rate of PPI. These findings suggest a more dominant impact of the TAVR procedure itself than patient risk factors when considering risk of conduction system injury. Patients eligible for surgical or percutaneous replacement should be counseled regarding risk regardless of age or other perceived favorable risk profiles.
\end{abstract}

KEYWORDS. Atrioventricular block, CoreValve, Evolut, pacemaker, transcatheter aortic valve replacement.
ISSN 2156-3977 (print) ISSN 2156-3993 (online)

(C) 2016 Innovations in Cardiac Rhythm Management

\footnotetext{
The authors report no conflicts of interest for the published content. Manuscript received June 28, 2016, Final version accepted August 8, 2016.

Address correspondence to: Rahul N. Doshi, MD, Director of Electrophysiology, Associate Professor of Medicine, University of Southern California, 1510 San Pablo Street, Suite 322, Los Angeles, CA 90033-5322. E-mail: Rahul.Doshi@med.usc.edu
}

\section{Introduction}

Severe aortic stenosis (AS) affects $2-4 \%$ of adults older than 75 years of age. ${ }^{1-3}$ Current guidelines recommend surgical aortic valve replacement (SAVR) as the firstline therapy for patients who are appropriate surgical candidates. Traditionally, transcatheter aortic valve 
replacement (TAVR) is recommended for patients who are not surgical candidates. ${ }^{4}$ However, in recent years TAVRs have been increasing in popularity. ${ }^{5}$ The OBSERVANT trial demonstrated no significant difference in mortality between SAVR and TAVR at 1 year in patients matched head to head, many of which had a more favorable risk profile than is typical of most TAVR patients. ${ }^{6}$ TAVR is quickly gaining widespread use with the potential for expanded indications. Thus, any potential complication needs to be thoroughly characterized.

High-degree atrioventricular (AV) block requiring permanent pacemaker implantation (PPI) is an important and well-known complication of TAVR. This complication happens more frequently in TAVR than in SAVR. ${ }^{7-9}$ The OBSERVANT study demonstrated a $3.6 \%$ versus $15.5 \%(\mathrm{p}<0.001)$ pacemaker implantation rate for SAVR versus TAVR. ${ }^{6}$ The study included patients that underwent TAVR with either the Edwards SAPIEN@ valve (Edwards Lifesciences, Irvine, CA) or the Medtronic CoreValve@ (Medtronic Inc., Minneapolis, MN). Current literature has shown that these two devices have very different post-procedural PPI rates. Studies have found a PPI rate of $18-34 \%$ for the CoreValve $\odot$ versus $4-12 \%$ for the SAPIEN@ valve (Edwards Lifesciences, Irvine, CA). ${ }^{9-17}$ Additionally, the CoreValve $\odot$ has been associated with a higher incidence of procedural related left bundle branch block (LBBB) than the SAPIEN@) ${ }^{16-20}$ It is not yet fully understood what causes these marked differences.

Although the CoreValve $\odot$ is more likely to cause conduction abnormalities than SAPIEN@ valve, this has not manifested itself in overall mortality. Neither the UK-TAVI or the FRANCE-2 trial reveal a significant difference in mortality between the two valves. ${ }^{21,22}$ The majority of data suggests a neutral effect, but there is evidence that patients who require PPI after TAVR have a higher mortality at 1 year than patients who did not require pacemaker implantation. ${ }^{23}$ A subgroup analysis from the PARTNER study also demonstrates that PPI was associated with lower ejection fractions at 1 year. ${ }^{23}$ Thus, in patients with severe aortic stenosis undergoing TAVRs, it is important to identify which patients are at high risk for post-procedure PPI to better tailor their management and therapies.

Patients who receive therapy after commercial release may show differences with expanded indications or without the stringent guidelines of a Pivotal Trial. Thus, complication rates may be different in this group. Moreover, next-generation devices may also differ and their complication rates should be validated in a real-world population. For this reason, we sought to analyze the PPI rate in our large, single-center CoreValve $\odot$ (Medtronic Inc., Minneapolis, MN) experience, and compare rates between those enrolled in the Pivotal Trial with those implanted since approval.

\section{Materials and methods}

This was a retrospective study that analyzed a cohort of patients who underwent TAVR at the University of Southern California Keck Medical Center from July 2011 to May 2016. The protocol was reviewed and approved by our Institutional Review Board. A total of 178 patients underwent TAVR during this time period. All TAVR procedures were performed using a self-expanding CoreValve $(\mathcal{C}$ or Evolut $(\subset)$ system; the procedure approach was selected at the discretion of the attending physicians. Valves were implanted through a retrograde transfemoral direct aortic approach.

Sixty of the patients included were part of the United States Pivotal Trial (study patients) and 91 of the patients received the CoreValve $\odot$ after Federal Drug Administration approval. Thirty-two patients received the Evolut(C) next-generation valve. Twenty-five patients from the study group and 13 from the commercial group were excluded because they either had a prior permanent pacemaker/defibrillator or their TAVR was converted into a surgical replacement mid-procedure (18/25 and 7/ 25 from the study group; 11/13 and 2/13 from the PMA group, respectively). Five patients were excluded from the Evolut $\odot$ group for prior pacemaker implantation. For each patient, demographic, electrocardiogram, past medical and surgical history, home medications, and post-procedural pacing parameters were recorded.

\section{Statistical analysis}

Categorical data are presented as number and percentage, and continuous variables are presented as the mean \pm standard deviation. Statistical analysis was performed using the SAS version 9.2 (SAS Institute Inc). The Student $t$ test was used to compare continuous variables, and the chi-square test or Fisher exact test was used to compare categorical variables. Univariate and multivariate analyses by logistic regression were conducted to identify variables independently associated with pacemaker implant. Using stepwise logistic regression analysis, the following variables from univariate analysis were entered into a multivariate model: age, gender, QRS $>120$, prior conduction disease, prior atrial fibrillation (AF) and balloon valvuloplasty. All probabilities were two-sided, and $\mathrm{p} \leq 0.05$ was considered significant.

\section{Results}

In total 140 patients were analyzed. Table 1 shows the baseline characteristics for the total patient population and subgroups. The average age in the total population was $81.2 \pm 8.9$ years. The average age in the Pivotal Trial population was older than either the PMA group or the Evolut $\odot$ group $(85.1 \pm 8.0$ versus $80.2 \pm 9.0$ and $78.7 \pm 8.1$, $\mathrm{p}=0.0006$ ). Fifty-six percent of the PMA group and $54 \%$ of the Pivotal Trial group were male as opposed to $29.6 \%$ in the Evolut $\odot$ group $(p=0.04)$. There was no significant difference in the proportion of patients with prior conduction disease between the two groups, nor in the percentage of patients with history of coronary artery bypass or other cardiac procedure. A higher percentage of the patients in the Evolut $\odot$ group were on $\beta$-blockers. Table 2 shows the rate of pacemaker implantation. The overall rate of pacemaker implantation was $39.3 \%$ in the total population. The most common indication for 
Table 1: Demographics table (all population) $(\mathrm{N}=140)$

\begin{tabular}{|c|c|c|c|c|}
\hline & All population $(\mathrm{N}=140)$ & Commercial + study $(\mathrm{N}=113)$ & Evolut $\odot(N=27)$ & $\mathbf{p}$ \\
\hline Age & $81.15 \pm 8.88$ & $81.74 \pm 8.98$ & $78.67 \pm 8.13$ & 0.11 \\
\hline Male & $72(51.43)$ & $64(56.64)$ & $8(29.63)$ & 0.01 \\
\hline Female & $68(48.57)$ & $49(43.36)$ & $19(70.37)$ & 0.01 \\
\hline \multicolumn{5}{|l|}{ Pre-PPM implant conduction disease } \\
\hline First-degree heart block & $29(20.71)$ & $21(18.58)$ & $8(29.63)$ & 0.20 \\
\hline Second-degree heart block (Mobitz Type I) & $2(1.43)$ & $1(0.88)$ & $1(3.70)$ & 0.35 \\
\hline Second-degree heart block (Mobitz Type II) & $1(0.71)$ & $1(0.88)$ & $0(0)$ & 1.0 \\
\hline Third-degree heart block & $0(0)$ & $0(0)$ & $0(0)$ & 1.0 \\
\hline RBBB & $25(17.86)$ & $23(20.35)$ & $2(7.41)$ & 0.16 \\
\hline LBBB & 13(9.29) & $12(10.62)$ & $1(3.70)$ & 0.46 \\
\hline Prior conduction disease & $64(45.71)$ & $52(46.02)$ & $12(44.44)$ & 0.88 \\
\hline QRS $>120$ & $51(36.43)$ & $42(37.17)$ & $9(33.33)$ & 0.71 \\
\hline Average QTC & $436.80 \pm 36.26$ & $436.80 \pm 37.10$ & $436.90 \pm 33.14$ & 0.99 \\
\hline Average QRS & $112.74 \pm 28.79$ & $113.40 \pm 29.39$ & $110.0 \pm 26.47$ & 0.58 \\
\hline Prior AF & $42(30.0)$ & $38(33.63)$ & $4(14.81)$ & 0.06 \\
\hline Average $\mathrm{EF}$ & $56.99 \pm 14.50$ & $57.22 \pm 14.72$ & $56.0 \pm 13.76$ & 0.70 \\
\hline Prior CABG & 29(20.71) & $22(19.47)$ & $7(25.93)$ & 0.46 \\
\hline Other prior cardiac procedure & $35(25.0)$ & $28(24.78)$ & $7(25.93)$ & 0.90 \\
\hline Prior cardiac surgery including CABG & $60(42.86)$ & $50(44.25)$ & $10(37.04)$ & 0.50 \\
\hline Medications & $111(79.29)$ & $89(78.76)$ & $22(81.48)$ & 0.75 \\
\hline$\beta$-Blocker & $80(57.14)$ & $59(52.21)$ & $21(77.78)$ & 0.02 \\
\hline Calcium channel blocker & $32(22.86)$ & $27(23.89)$ & $5(18.52)$ & 0.55 \\
\hline Digoxin & $16(11.43)$ & $16(14.16)$ & $0(0)$ & 0.04 \\
\hline Amiodarone/other & $21(15.0)$ & $18(15.93)$ & $3(11.11)$ & 0.77 \\
\hline \multirow{2}{*}{\multicolumn{5}{|c|}{ Indication for PPM }} \\
\hline & & & & \\
\hline First-degree heart block & $2(1.43)$ & $2(1.77)$ & $0(0)$ & 1.0 \\
\hline Second-degree heart block (Mobitz Type I) & $7(5.0)$ & $6(5.31)$ & $1(3.70)$ & 1.0 \\
\hline Second-degree heart block (Mobitz Type II) & $3(2.14)$ & $3(2.65)$ & $0(0)$ & 1.0 \\
\hline Third-degree heart block & $29(20.71)$ & $24(21.24)$ & $5(18.52)$ & 0.75 \\
\hline \multicolumn{5}{|l|}{ Pacing } \\
\hline Next day & $2(1.43)$ & $1(0.88)$ & $1(3.70)$ & 0.35 \\
\hline 1 week & $2(1.43)$ & $1(0.88)$ & $1(3.70)$ & 0.35 \\
\hline 1 month & $1(0.71)$ & $1(0.88)$ & $0(0)$ & 1.0 \\
\hline 3 months & $1(0.71)$ & $1(1.28)$ & $0(0)$ & 1.0 \\
\hline Other & $8(5.71)$ & $8(7.08)$ & $0(0)$ & 0.35 \\
\hline Mortality & $16(11.43)$ & $16(14.16)$ & $0(0)$ & 0.04 \\
\hline Other complications excluding death & $5(3.57)$ & $5(4.42)$ & $0(0)$ & 0.58 \\
\hline
\end{tabular}

Continuous variables are expressed as mean \pm SD. Categorical variables are expressed as a percentage.

AF: atrial fibrillation; CABG: coronary artery bypass graft; EF: ejection fraction; LBBB: left bundle branch block; PPM: Permanent Pacemaker; RBBB: right bundle branch block.

Table 2: Indication for PPM based on total PPM implant numbers (all population) $(\mathrm{N}=140)$

\begin{tabular}{lccc}
\hline & Commercial + study $(\mathbf{N}=\mathbf{4 9})$ & Evolut $(\mathbf{N}=\mathbf{6})$ & $\mathbf{p}$ \\
\hline PPM implant & $49(100.0)$ & $6(100.0)$ & 1.0 \\
Indication for PPM & & & \\
First-degree heart block & $2(4.08)$ & $0(0)$ & 1.0 \\
Second-degree heart block (Mobitz Type I) & $6(12.24)$ & $1(16.67)$ & 0.58 \\
Second-degree heart block (Mobitz Type II) & $3(6.12)$ & $0(0)$ & 1.0 \\
Third-degree heart block & $24(48.98)$ & $5(83.33)$ & 0.20 \\
\hline
\end{tabular}

PPM: Permanent Pacemaker.

pacemaker in the entire population was third-degree heart block (53\%). There was no significant difference in pacemaker indications between the three groups. There was no significant difference in pacemaker implantation rate between the two groups receiving the CoreValve $\odot$ in the PMA group versus the Pivotal Trial group $(44.9 \%$ versus $40.0 \% ; \mathrm{p}=0.63$ ). This is graphically depicted in Figure 1. However, the Evolut $(\mathrm{C}$ group had a rate of
$22.2 \%$. When the three groups are compared, the value did not reach statistical significance $(p=0.12)$, but when the Evolut group is compared with the total CoreValve() population, this reached statistical significance $(\mathrm{p}=0.04)$ as shown in Figure 2.

Univariate analysis for the total population is depicted in Table 3. When analysis was performed for the total population, only QTc and history of AF were found to be 


\section{Rates Pacemaker Implantation (\%)}

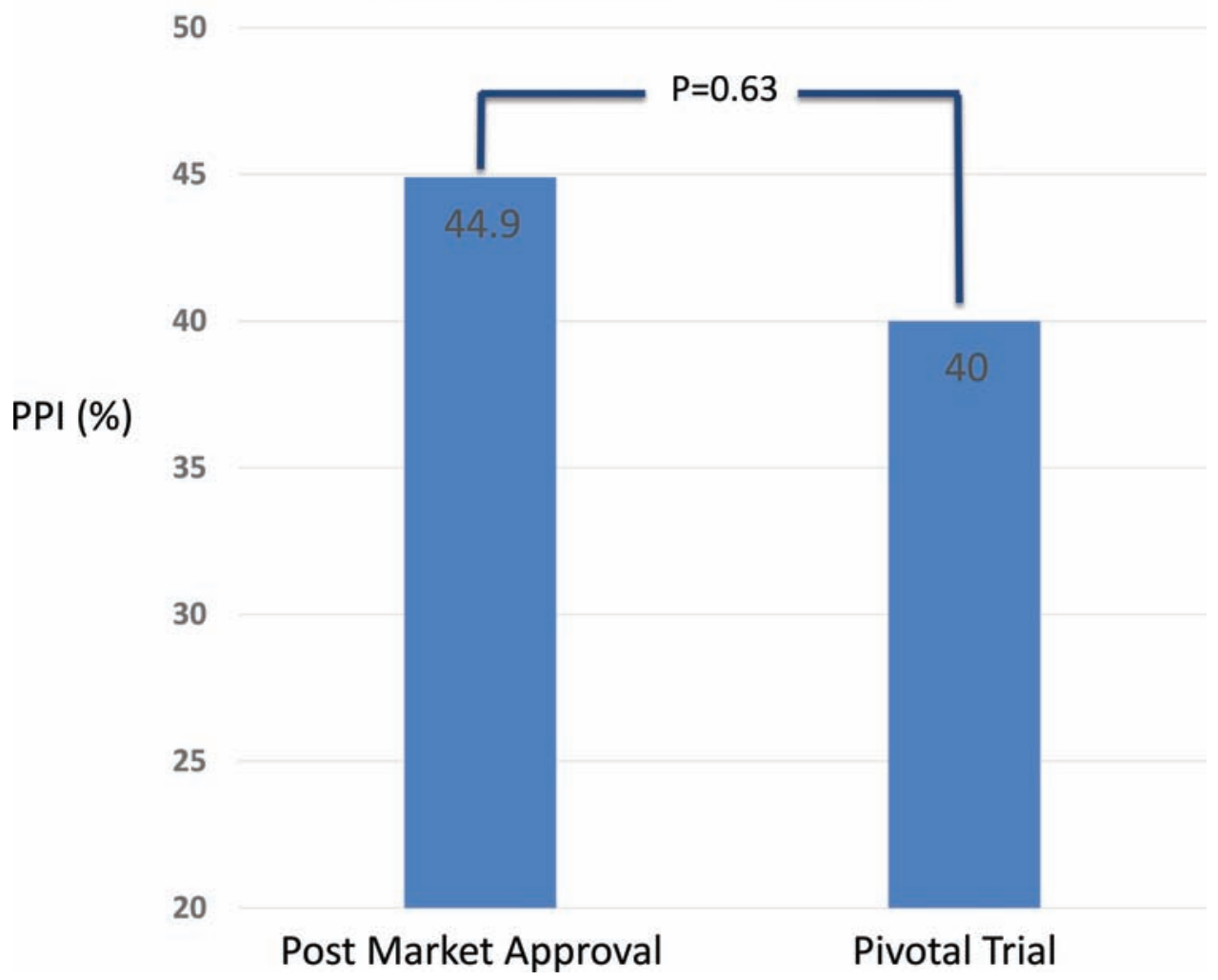

Figure 1: Pacemaker implantation rates for Pivotal Trial versus post-market approval group. PI: Pacemaker Implantation; PT: Pivotal Trial group; PMA: Permanent Pacemaker Implantation.

predictors of PPI. However, right bundle branch block (RBBB) almost reached statistical significance with $\mathrm{p}=0.06$. Multivariate analysis for the entire population is depicted in Figure 3. A history of $\mathrm{AF}$, the presence of RBBB, male gender, and AV nodal blocking drugs showed trends towards but failed to reach statistical significance.

Multivariate analysis of the total population compared to subgroups is shown in Figure 4. Factors were identified by prior univariate analysis. In the total population, prior conduction system disease and AF were demonstrated to be significant predictors of PPI (OR 2.29-5.28, $\mathrm{p}=0.05$, and OR 2.77-7.19, $\mathrm{p}=0.04$, respectively). Male gender and AV nodal blockers showed a positive trend but did not reach statistical significance. Balloon valvuloplasty prior to TAVR for AS was a predictor in the PMA group (OR 3.3-9.94, $\mathrm{p}=0.03$ ), with male gender, conduction disease, and prior AF failing to reach statistical significance. This was similar in the Pivotal Trial group with the same variables suggestive but not reaching statistical significance. No variables were shown to be predictive in the Evolut $\odot$ group.

\section{Discussion}

Our rate of PPI (39.3\%) was similar to what is seen in the literature but somewhat higher. ${ }^{8-17,21,24,25}$ This may reflect differences in our population compared with the entire Pivotal Trial cohort or the general population post approval or perhaps a broader indication. The rate of high-grade AV block (complete heart block or Mobitz II second-degree block) was $22.9 \%$. In our study, the PMA group was significantly younger than the Pivotal Trial group. In addition, the TAVR procedures completed in the PMA group were performed after the experience gained in the Pivotal Trial. Yet, the rate of PPI was not significantly different. This suggests that the CoreValve $\odot$ has an effect on the cardiac conduction system independent of discernible patient risk factors. Furthermore, in our analysis only $\mathrm{AF}$ and prior conduction disease were shown to be significant risk factors for PPI.

We postulate that the high pacemaker implantation risk of CoreValve $\odot$ stems from a combination of mechanical disruption by the new valve in an already susceptible patient. More specifically, the self-expanding feature itself of the Medtronic CoreValve( $)$ system may play an important role in this mechanical disruption. The AV node is located on the central fibrous body in the muscular portion of the AV septum. The bundle of His extends from the $\mathrm{AV}$ node rightward. It then enters the posteroinferior portion of the membranous septum and the crest of the muscular septum, forming part of the left ventricular outflow tract (LVOT) ${ }^{26}$ In an autopsy series of elderly patients, approximately $30 \%$ of subjects had a leftward AV bundle, and in $20 \%$ the bundle coursed just underneath the endocardium on the membranous septum. ${ }^{27}$ The selfexpanding skirt of the Medtronic CoreValve $\odot$ applies outward pressure over this area, which may put strain on the bundle of His and possibly the AV node, consequently 


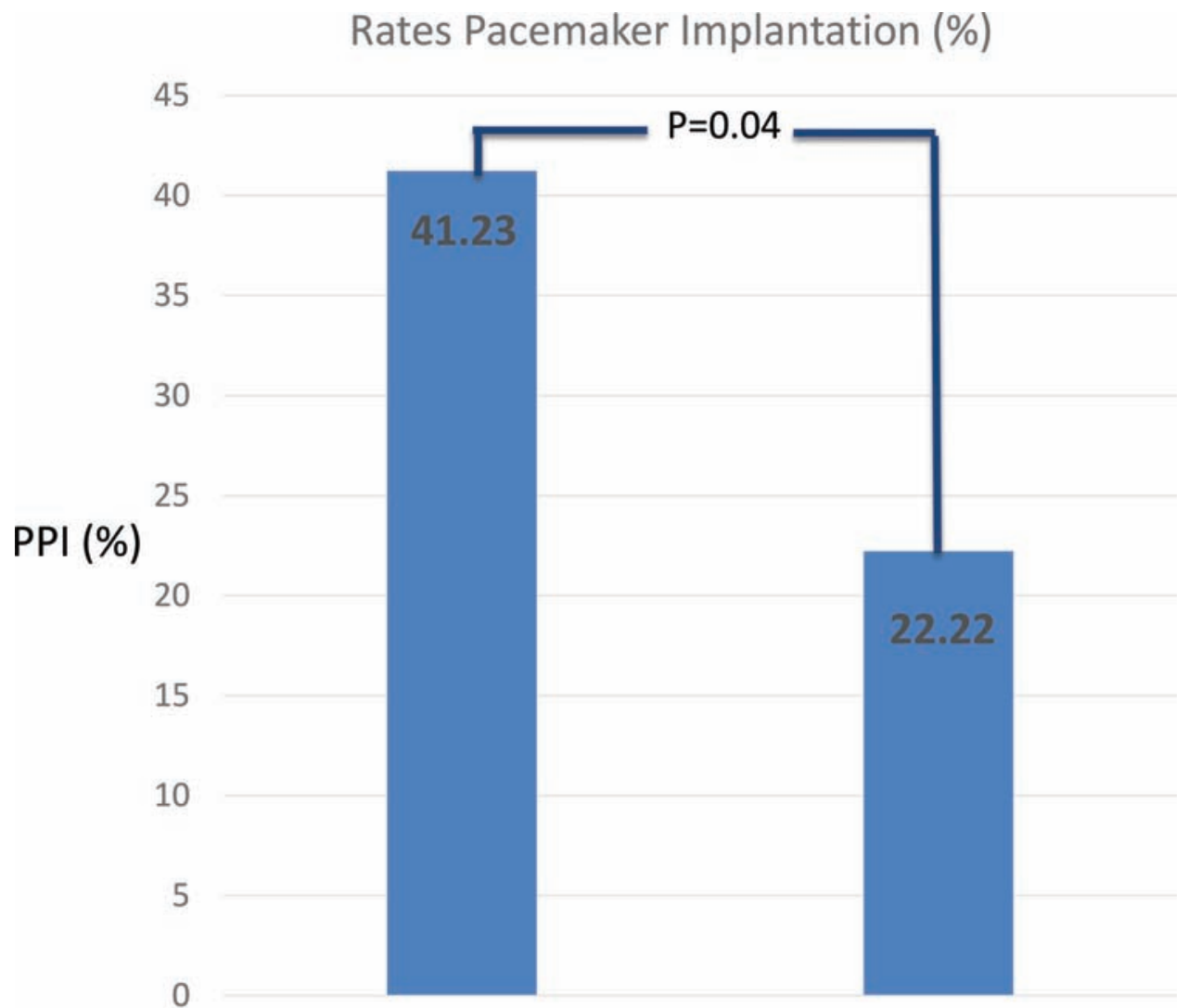

Total CoreValve

Evolut Valve

Figure 2: Pacemaker implantation rates total CoreValve population versus next generation Evolut valve.

Table 3: Univariate: total population $(\mathrm{N}=140)$

\begin{tabular}{|c|c|c|c|}
\hline \multirow[t]{2}{*}{ Variable } & \multicolumn{3}{|c|}{ PPM implant $(\mathrm{N}=55)$} \\
\hline & Odds ratio & $95 \% \mathrm{Cl}$ & $\mathbf{p}$ \\
\hline Male & $1.77(n=33)$ & $0.89-3.52$ & 0.10 \\
\hline First-degree heart block & $0.93(n=11)$ & $0.40-2.16$ & 0.87 \\
\hline Second-degree heart block (Type I) & $7.98(n=2)$ & $0.19-333.86$ & 0.28 \\
\hline Second-degree heart block (Type II) & $4.65(n=1)$ & $0.05-428.64$ & 0.51 \\
\hline $\mathrm{RBBB}+\mathrm{LBBB}$ & $1.93(n=20)$ & $0.88-4.25$ & 0.10 \\
\hline Conduction disease & $1.74(n=34)$ & $0.87-3.47$ & 0.12 \\
\hline QTc (per 5 ms) & $1.05(n=55)$ & $1.0-1.02$ & 0.05 \\
\hline QRS (per $5 \mathrm{~ms}$ ) & $1.05(n=55)$ & $0.99-1.11$ & 0.14 \\
\hline $\mathrm{QRS}>120$ & $1.29(n=22)$ & $0.64-2.60$ & 0.48 \\
\hline Prior AF & $2.17(n=22)$ & $1.04-4.53$ & 0.04 \\
\hline Medications & $1.57(n=46)$ & $0.66-3.76$ & 0.31 \\
\hline$\beta$-Blocker & $1.07(n=32)$ & $0.54-2.13$ & 0.84 \\
\hline Calcium channel blocker & $1.77(n=16)$ & $0.80-3.92$ & 0.16 \\
\hline Digoxin & $2.18(n=9)$ & $0.76-6.25$ & 0.15 \\
\hline Amiodarone/other & $0.94(n=8)$ & $0.36-2.45$ & 0.90 \\
\hline
\end{tabular}

AF: atrial fibrillation; CABG: coronary artery bypass graft; LBBB: left bundle branch block; RBBB: right bundle branch block. 


\begin{tabular}{|l|l|l|l|}
\hline \multirow{2}{*}{ Variable } & \multicolumn{3}{|c|}{ PPM Implant $(\mathrm{N}=55)$} \\
\cline { 2 - 4 } & Odds Ratio & $95 \%$ CI & $\mathrm{p}$ Value \\
\hline Male & $1.86(\mathrm{n}=33)$ & $0.89-3.89$ & 0.10 \\
\hline Age (per 10 yrs) & $1.10(\mathrm{n}=55)$ & $0.73-1.69$ & 0.65 \\
\hline RBBB & $2.14(\mathrm{n}=14)$ & $0.85-5.34$ & 0.11 \\
\hline Prior AF & $2.14(\mathrm{n}=22)$ & $0.85-5.34$ & 0.07 \\
\hline AV nodal blockers (CCB, Beta Blockers, Digoxin) & $1.92(\mathrm{n}=44)$ & $0.82-4.49$ & 0.13 \\
\hline Amiodarone/other antiarrhythmic & $0.70(\mathrm{n}=8)$ & $0.22-2.17$ & 0.53 \\
\hline Prior Cardiac Procedure & $0.80(\mathrm{n}=22)$ & $0.37-1.71$ & 0.56 \\
\hline
\end{tabular}

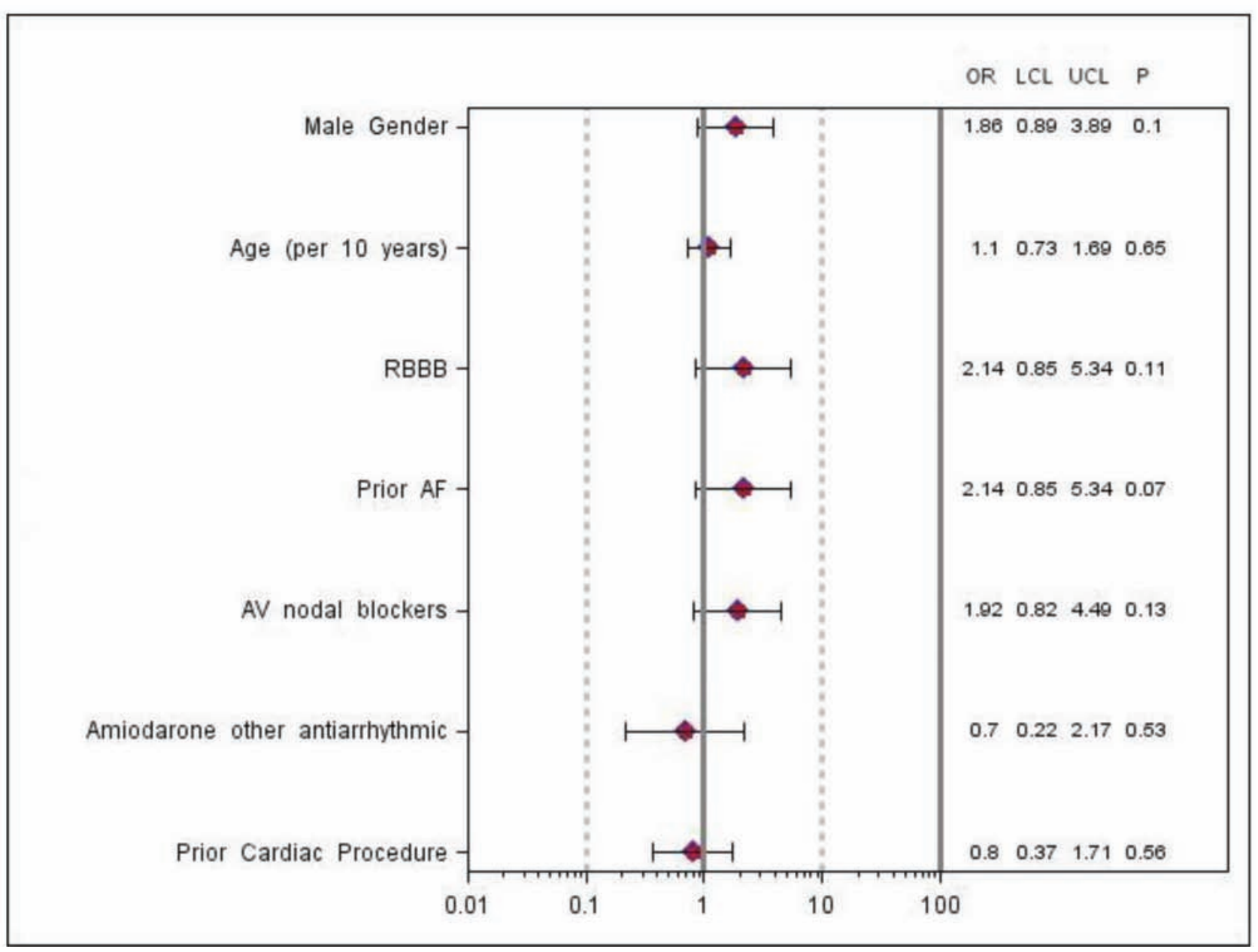

Figure 3: Multivariate analysis for total population and study groups. OR: odds ratio; LCL: lower confidence interval; UCL: upper confidence interval.

leading to mechanically injury. With this in mind, it is easy to see why patients with pre-existing conduction disease would be at particular risk for high-grade AV block post TAVR. It is no surprise that RBBB is the most powerful predictor for PPI, given the high likelihood of LBBB after Medtronic CoreValve@ placement. ${ }^{28}$ The depth of implantation in the LVOT is predictive of the rate of PPI with the Medtronic CoreValve ${ }^{29}$. Thus, larger valves implanted (i.e. 31-mm valves) would result in a larger number of conduction system abnormalities. This mechanism is also supported by the increased rate of pacemaker implantation with the ESV S3 valve compared with the ESV XT valve, in which the stent and increase in mesh fabric extends further into the LVOT. $^{30}$

It is somewhat controversial whether PPI adversely affects long-term outcome and mortality after TAVR. ${ }^{31}$ Data from the PARTNER study and registry demonstrate that PPI is associated with a longer hospital stay and risk of subsequent hospitalization. ${ }^{28}$ The data also reveal an increase in the composite endpoint of death and repeat hospitalization. ${ }^{28}$ There are many potential explanations for poorer outcome in patients requiring pacemaker implantation after TAVR. Certainly, this may be reflective of more advanced disease or 
Total CoreValve $(\mathrm{N}=140)$

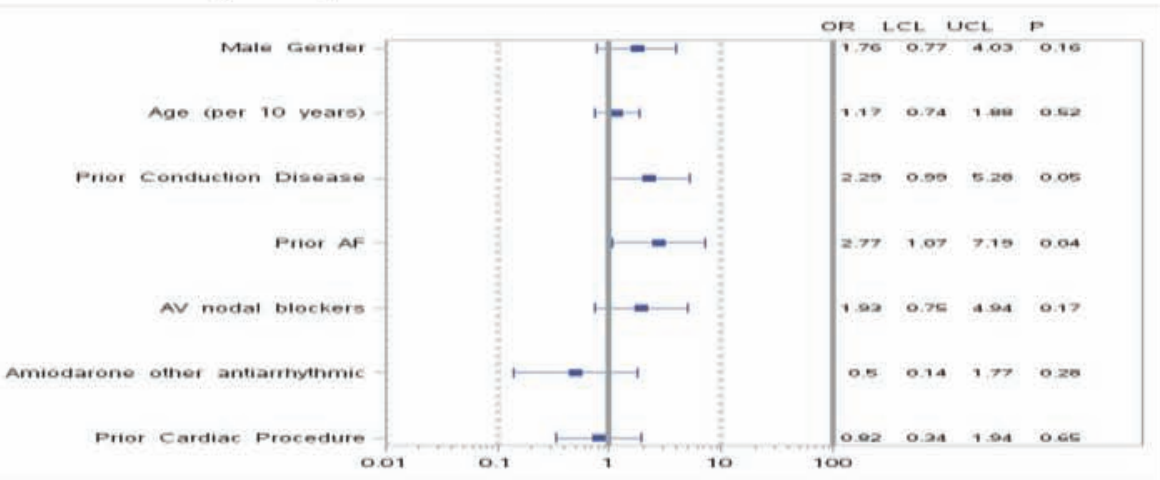

Post-Market Approval (PMA) Group (N=78)

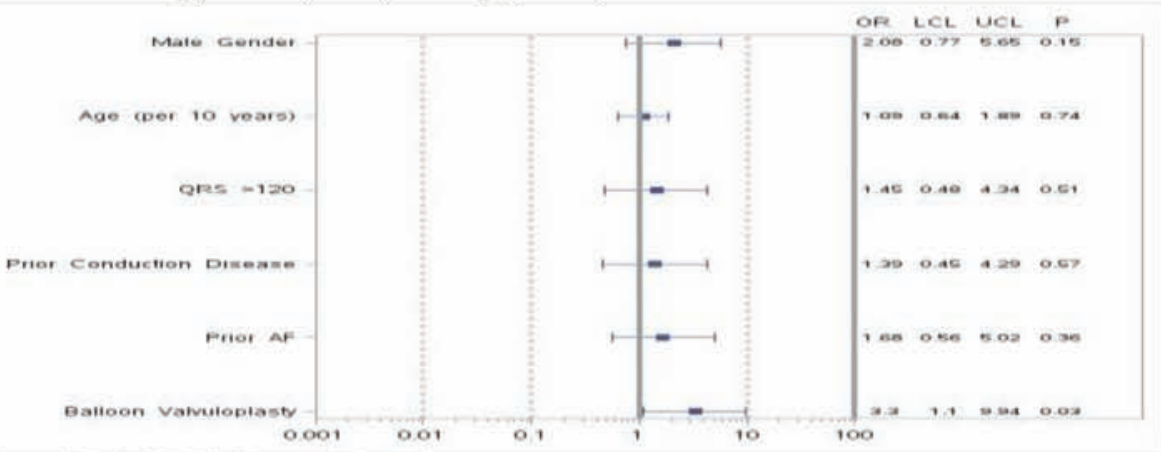

Pivotal Trial (PT) Group (N=35)

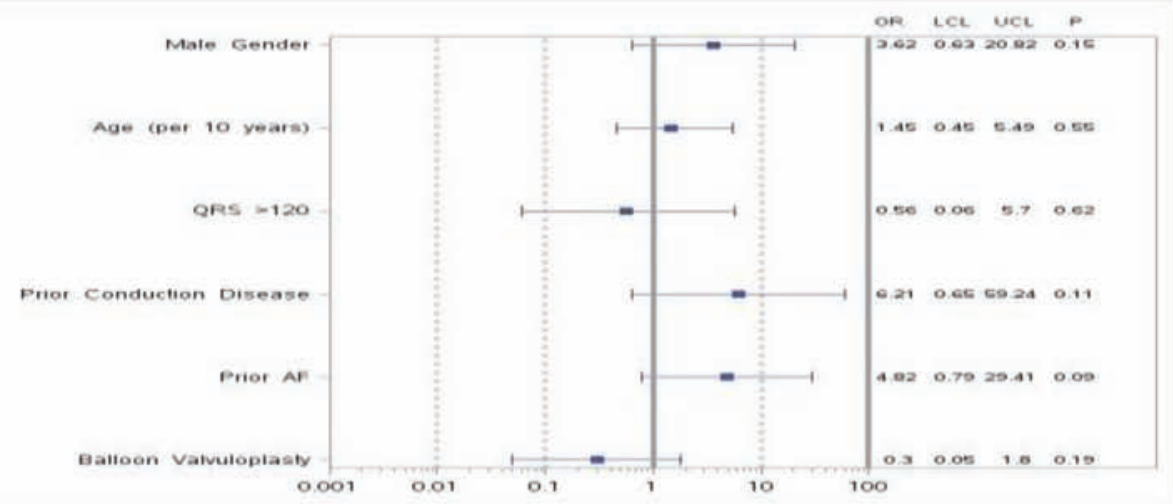

Evolut Valve Group ( $\mathrm{N}=27)$

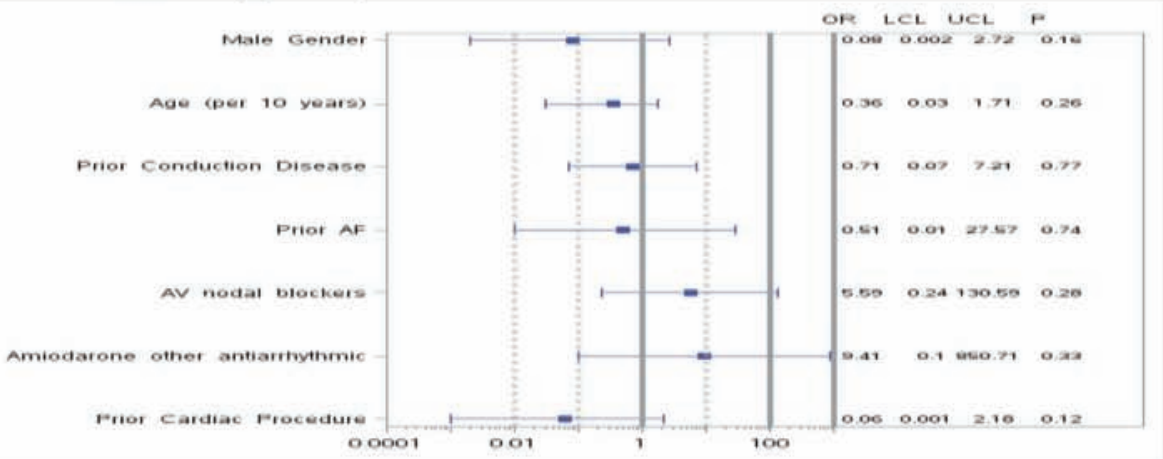

Figure 4: Multivariate analysis subgroups.

significant comorbidities. Our data suggest that only pre-existing conduction system disease and $\mathrm{AF}$ are predictive of PPI. Patients in our PMA group were also younger than the Pivotal Trial recipients. Operator experience did not significantly alter PPI rates between the Pivotal Trial and PMA groups. Taken together, these 
data suggest that the risk of PPI may be more related to the CoreValve $\odot$ device and implant procedure. Furthermore, given the high incidence of conduction disease among candidates for TAVR, risk stratification becomes more challenging.

Our data demonstrate a significant decrease in PPI rate with the next generation Evolut $\odot$ valve at $22.2 \%$, which is similar to other published data. ${ }^{32}$ This improvement is highly significant and represents an important advancement that will hopefully translate to long-term clinical benefits. However, heart block remains a significant complication of TAVR. Its impact including the potential for pacing-induced dyssynchrony leading to decline in left ventricular function has yet to be well delineated in this population. Recently, a meta-analysis of patients post TAVR with LBBB or PPI demonstrated a trend toward an increase in mortality with LBBB with a relative risk of 1.39, with early PPI negating this risk. ${ }^{33}$ Periprocedural PPI itself was not associated with an increase in mortality. Post-TAVR LBBB and pacing-induced dyssynchrony may be reasons for worsened outcomes in this population. ${ }^{34}$ Indeed, further investigation including whether or not cardiac resynchronization therapy has a role in this population needs to be pursued.

Of equal importance is the need to determine whether or not unnecessary PPI post-TAVR is associated with worsened outcomes. The self-expanding nature of the CoreValve $\odot$ system has led to the belief that early conduction system disturbances may simply predict future need for PPI and that early PPI may mitigate the risk of adverse events related to progressive conduction system disease. However, a recent report suggests that among patients with new LBBB post TAVR, the need for pacing for high-grade AV block is very low. ${ }^{35}$ Thus, the potential for worsening outcomes with new LBBB is more likely secondary to ventricular dyssynchrony rather than progressive conduction system disease. Interestingly, a retrospective analysis of CoreValve $\odot$ patients who developed post-TAVR heart block revealed a high percentage of patients with eventual conduction system recovery. ${ }^{28,36}$ This underscores the importance of determining when pacemaker implantation is absolutely necessary after TAVR. Studies such as the Ambulatory Electrocardiographic Monitoring for the Detection of High-Degree AtrioVentricular Block in Patients With New-Onset Persistent Left Bundle Branch Block After Transcatheter Aortic Valve Implantation (MARE) study (NCT02153307) will hopefully provide answers to this question.

\section{Study limitations}

This was a retrospective analysis from a single center and thus subject to potential bias. However, the comparisons made were in subjects performed by the same operators and facility. In addition, the relatively small numbers may not allow for adequate power for subgroup analysis.

\section{Conclusions}

Our study demonstrates that the rate of PPI after postmarket approval of the Medtronic CoreValve@ is no different from that of the Pivotal Trial. Antecedent conduction system disease and AF were the only predictors of pacemaker implantation, and the next generation Evolut $($ ) valve is associated with a decreased PPI rate. Further studies are needed to determine if this translates to better long-term clinical outcomes, and whether or not alternative strategies to mitigate the risks of conduction system abnormalities are effective.

\section{References}

1. Supino PG, Borer JS, Preibisz J, Bornstein A. The epidemiology of valvular heart disease: A growing public health problem. Heart Fail Clin. 2006;2(4):379-393.

2. Rashedi N, Otto CM. Aortic stenosis: Changing disease concepts. J Cardiovasc Ultrasound. 2015; 23(2):59-69.

3. Czarny MJ, Resar JR. Diagnosis and management of valvular aortic stenosis. Clin Med Insights Cardiol. 2014;8(Suppl. 1): $15-24$

4. Vahanian A, Alfieri O, Andreotti F, et al. [Guidelines on the management of valvular heart disease (version 2012). The Joint Task Force on the Management of Valvular Heart Disease of the European Society of Cardiology (ESC) and the European Association for Cardio-Thoracic Surgery (EACTS)]. G Ital Cardiol (Rome). 2013;14(3):167-214.

5. Agarwal S, Tuzcu EM, Stewart W, Bajaj NS, Svensson LG, Kapadia SR. Comparison of multicenter registries and randomized control trials for transcatheter aortic valve replacement (TAVR). Indian Heart J. 2013;65(4):400-411.

6. Tamburino C, Barbanti M, D'Errigo P, et al; OBSERVANT Research Group. 1-Year outcomes after transfemoral transcatheter or surgical aortic valve replacement: Results from the Italian OBSERVANT Study. I Am Coll Cardiol. 2015; 66(7):804-812.

7. Egger F, Nürnberg M, Rohla M, et al. High-degree atrioventricular block in patients with preexisting bundle branch block or bundle branch block occurring during transcatheter aortic valve implantation. Heart Rhythm. 2014;11(12): 2176-2182.

8. Khawaja MZ, Rajani R, Cook A, et al. Permanent pacemaker insertion after CoreValve transcatheter aortic valve implantation: Incidence and contributing factors (the UK CoreValve Collaborative). Circulation. 2011;123(9): 951-960.

9. Siontis GC, Jüni P, Pilgrim T, et al. Predictors of permanent pacemaker implantation in patients with severe aortic stenosis undergoing TAVR: A meta-analysis. J Am Coll Cardiol. 2014;64(2):129-140.

10. Himbert D, Descoutures F, Al-Attar N, et al. Results of transfemoral or transapical aortic valve implantation following a uniform assessment in high-risk patients with aortic stenosis. J Am Coll Cardiol. 2009;54(4):303-311.

11. Mussardo M, Latib A, Chieffo A, et al. Periprocedural and short-term outcomes of transfemoral transcatheter aortic valve implantation with the Sapien $\mathrm{XT}$ as compared with the Edwards Sapien valve. JACC Cardiovasc Interv. 2011;4(7): 743-750.

12. Bleiziffer S, Ruge H, Hörer J, et al. Predictors for new-onset complete heart block after transcatheter aortic valve implantation. JACC Cardiovasc Interv. 2010;3(5):524-530.

13. Attias D, Himbert D, Ducrocq G, et al. Immediate and midterm results of transfemoral aortic valve implantation using either the Edwards Sapien transcatheter heart valve or the Medtronic CoreValve System in high-risk patients with aortic stenosis. Arch Cardiovasc Dis. 2010;103(4):236-245. 
14. Godino C, Maisano F, Montorfano M, et al. Outcomes after transcatheter aortic valve implantation with both Edwards-SAPIEN and CoreValve devices in a single center: The Milan experience. JACC Cardiovasc Interv. 2010;3(11): 1110-1121.

15. Ferreira ND, Caeiro D, Adão L, et al. Incidence and predictors of permanent pacemaker requirement after transcatheter aortic valve implantation with a self-expanding bioprosthesis. Pacing Clin Electrophysiol. 2010;33(11):1364-1372.

16. Erkapic D, Kim WK, Weber M, et al. Electrocardiographic and further predictors for permanent pacemaker requirement after transcatheter aortic valve implantation. Europace. 2010;12(8):1188-1190.

17. Sinhal A, Altwegg L, Pasupati S, et al. Atrioventricular block after transcatheter balloon expandable aortic valve implantation. JACC Cardiovasc Interv. 2008;1(3):305-309.

18. Franzoni I, Latib A, Maisano F, et al. Comparison of incidence and predictors of left bundle branch block after transcatheter aortic valve implantation using the CoreValve versus the Edwards valve. Am J Cardiol. 2013;112(4):554-559.

19. Roten L, Wenaweser P, Delacrétaz E, et al. Incidence and predictors of atrioventricular conduction impairment after transcatheter aortic valve implantation. Am J Cardiol. 2010; 106(10):1473-1480.

20. Piazza N, Onuma Y, Jesserun E, et al. Early and persistent intraventricular conduction abnormalities and requirements for pacemaking after percutaneous replacement of the aortic valve. JACC Cardiovasc Interv. 2008;1(3):310-316.

21. Moat NE, Ludman P, de Belder MA, et al. Long-term outcomes after transcatheter aortic valve implantation in highrisk patients with severe aortic stenosis: The U.K. TAVI (United Kingdom Transcatheter Aortic Valve Implantation) Registry. J Am Coll Cardiol. 2011;58(20):2130-2138.

22. Gilard $M$, Eltchaninoff $H$, Iung $B$, et al; FRANCE 2 Investigators. Registry of transcatheter aortic-valve implantation in high-risk patients. N Engl J Med. 2012;366(18): 1705-1715.

23. Dizon JM, Nazif TM, Hess PL, et al. PARTNER Publications Office. Chronic pacing and adverse outcomes after transcatheter aortic valve implantation. Heart. 2015;101(20):1665-1671.

24. Kawaguchi AT, D'Allessandro C, Collet JP, Cluzel P, Makri $\mathrm{R}$, Leprince P. Ventricular conduction defects after transcatheter aortic valve implantation: A single-institute analysis. Artif Organs. 2015;39(5):409-415.

25. Tracy CM. Pacemaker after transcatheter aortic valve replacement: Unexpected, but not infrequent outcome. J Am Coll Cardiol. 2014;64(2):141-143.
26. Kouchoukos N, Blackstone E, Hanley F, Kirklin J. Kirklin/ Barratt-Boyes Cardiac Surgery. 4th Ed. Philadelphia, PA: Elsevier Health Sciences; 2013:2256.

27. Kawashima T, Sato F. Visualizing anatomical evidences on atrioventricular conduction system for TAVI. Int J Cardiol. 2014;174(1):1-6.

28. Nazif TM, Dizon JM, Hahn RT, et al; PARTNER Publications Office. Predictors and clinical outcomes of permanent pacemaker implantation after transcatheter aortic valve replacement: The PARTNER (Placement of AoRtic TraNscathetER Valves) trial and registry. JACC Cardiovasc Interv. 2015;8(1)(1 Pt A):60-69.

29. Muñoz-García AJ, Hernández-García JM, Jiménez-Navarro $\mathrm{MF}$, et al. Changes in atrioventricular conduction and predictors of pacemaker need after percutaneous implantation of the CoreValve ${ }^{\mathbb{R}}$. Aortic valve prosthesis. Rev Esp Cardiol. 2010;63(12):1444-1451.

30. De Torres-Alba F, Kaleschke G, Diller GP, et al. Changes in the Pacemaker Rate After Transition From Edwards SAPIEN XT to SAPIEN 3 Transcatheter Aortic Valve Implantation: The Critical Role of Valve Implantation Height. JACC Cardiovasc Interv. 2016;9(8):805-813.

31. Buellesfeld L, Stortecky S, Heg D, et al. Impact of permanent pacemaker implantation on clinical outcome among patients undergoing transcatheter aortic valve implantation. J Am Coll Cardiol. 2012;60(6):493-501.

32. Manoharan G, Walton AS, Brecker SJ, et al. Treatment of symptomatic severe aortic stenosis with a novel resheathable supra-annular self-expanding transcatheter aortic valve system. JACC Cardiovasc Interv. 2015;8(10): 1359-1367.

33. Regueiro A, Abdul-Jawad Altisent O, Del Trigo M, et al. Impact of new-onset left bundle branch block and periprocedural permanent pacemaker implantation on clinical outcomes in patients undergoing transcatheter aortic valve replacement: A systematic review and meta-analysis. Circ Cardiovasc Interv. 2016;9(5):e003635.

34. Kutyifa V, Pouleur AC, Knappe D, et al. Dyssynchrony and the risk of ventricular arrhythmias. JACC Cardiovasc Imaging. 2013;6(4):432-444.

35. Akdemir B, Bekwelem W, Alraies C, et al. Pacemaker utilization in patients who develop new left bundle branch block after transcatheter aortic valve replacement. Heart Rhythm. 2016; 13(5, Suppl.):S166-S250.

36. Sidhu KD, Ng K, Leong-Sit P, et al. Do all patients with heart block post aortic valve replacement require a permanent pacemaker? Heart Rhythm. 2016;13(5, Suppl.):S515-S597. 